\title{
Influence of Tip Diameter and Light Spectrum of Curing Units on the Properties of Bulk-Fill Resin Composites
}

\author{
Igor Oliveiros Cardoso ${ }^{1}$ Alexandre Coelho Machado ${ }^{2}$ Luísa de Oliveira Fernandes ${ }^{1}$ \\ Paulo Vinícius Soares ${ }^{3}$ Luís Henrique Araújo Raposo1일
}

${ }^{1}$ Department of Occlusion, Fixed Prosthodontics and Dental Materials, School of Dentistry, Federal University of Uberlândia, Uberlândia, Brazil

${ }^{2}$ Technical School of Health, Federal University of Uberlândia, Uberlândia, Brazil

${ }^{3}$ Department of Operative Dentistry and Dental Materials, School of Dentistry, Federal University of Uberlândia, Uberlândia, Brazil
Address for correspondence Luís Henrique Araújo Raposo, DDS, MSc, $\mathrm{PhD}$, Department of Occlusion, Fixed Prosthodontics and Dental Materials, School of Dentistry, Federal University of Uberlandia, Avenue Pará, 1720, Bloco 4L, Sala 4LA42, Campus Umuarama, Uberlândia, MG 38400-902, Brazil (e-mail: raposo@ufu.br).

Eur J Dent 2022;16:360-366.

\begin{abstract}
Keywords

- resin composite

- light curing

- polymerization

Objective The aim of this study was to evaluate the influence of different light-curing units (LCUs) with distinct tip diameters and light spectra for activating bulk-fill resins. Materials and Methods The specimens $(n=10)$ were made from a conventional composite (Amaris, VOCO) and bulk-fill resins (Aura Bulk Fill, SDI; Filtek One, 3M ESPE; Tetric Bulk Fill, Ivoclar Vivadent) with two diameters, 7 or $10 \mathrm{~mm}, \times 2 \mathrm{~mm}$ thickness. Following 24 hours of specimen preparation, the degree of conversion (DC) was evaluated using the Fourier-transform infrared unit. Knoop hardness (KHN) readings were performed on the center and periphery of the specimens. Data were assessed for homoscedasticity and submitted to one-way and three-way analysis of variance followed by the Tukey's and Dunnett's tests, depending on the analysis performed $(\alpha=0.05)$.

Results LCUs and specimen diameter significantly affected the DC. The Tetric Bulk Fill provided increased DC results when light-cured with Valo (54.8 and 53.5\%, for 7 and $10 \mathrm{~mm}$, respectively) compared with Radii Xpert (52.1 and 52.9\%, for 7 and $10 \mathrm{~mm}$, respectively). No significant differences in $\mathrm{KHN}$ results were noted for the conventional resin composite (Amaris) compared with LCUs $(p=0.213)$ or disc diameters $(p=0.587)$, but the center of the specimen exhibited superior KHN $(p \leq 0.001)$ than the periphery.

Conclusion The light spectrum of the multipeak LCU (Valo) significantly increased the DC and KHN of the bulk-fill resin composite with additional initiator to camphorquinone (Tetric Bulk Fill) compared with the monowave LCU (Radii Xpert). The tip size of the LCUs influenced the performance of some of the resin composites tested.
\end{abstract}

published online

December 14, 2021
DOI https://doi.org/

$10.1055 / \mathrm{s}-0041-1735799$. ISSN 1305-7456.
(C) 2021. The Author(s).

This is an open access article published by Thieme under the terms of the Creative Commons Attribution License, permitting unrestricted use, distribution, and reproduction so long as the original work is properly cited. (https://creativecommons.org/licenses/by/4.0/)

Thieme Medical and Scientific Publishers Pvt. Ltd., A-12, 2nd Floor, Sector 2, Noida-201301 UP, India 


\section{Introduction}

Resin-based composites (RBCs) are widely used materials for Classes I and II restorations with failure rates of $1.8 \%$ after 5 years and $2.4 \%$ after 10 years. ${ }^{1}$ Although conventional RBCs exhibit good mechanical properties, they also present undesirable characteristics, such as polymerization shrinkage. ${ }^{2}$ This shrinkage results in residual stress in the tooth-restoration interface. If not controlled or reduced either by the operator or material, the shrinkage stress is related to marginal staining, enamel cracks, and postoperative sensitivity. $^{2}$ According to the World Dental Federation, direct restorations can fail based on aesthetic, functional, or biological aspects. ${ }^{3}$ Shrinkage stress may be related with all these criteria regardless of whether manifested early or in late stages, leading to failures. ${ }^{3}$ Some measures can be taken to reduce the influence of polymerization shrinkage; for example, the use of incremental insertion techniques or bulk-fill composite materials would be beneficial for the final restoration. ${ }^{4}$ Beyond decreasing the clinical time of the restorative procedure, bulk-fill resin composites are used in single increments of up to 4 or $5 \mathrm{~mm}$ thickness because they present lower polymerization shrinkage and consequently lower residual shrinkage stress. ${ }^{5}$

For RBCs restorations to be successful and acquire adequate mechanical and optical properties, proper polymerization is required. ${ }^{6}$ Some relevant properties for the success of a restoration, such as the degree of conversion (DC) and hardness, are influenced by irradiance and the light spectrum. ${ }^{6,7}$ The DC, namely, monomers converting to polymers, is directly related to hardness, a property that expresses the mechanical and wear resistance of resin-based composites. ${ }^{5,7}$ The light-curing unit (LCU) provides the light that will allow the activation of initiators present in the composites to trigger the polymerization process. ${ }^{7}$ Currently, the most widely used LCUs include light-emitting diodes (LED) that can present different spectra, and these devices are classified into monowave and multipeak units. ${ }^{8}$ Monowave LED units present a light spectrum between 450 and $490 \mathrm{~nm}$. This light spectrum is effective in activating the camphorquinone (CQ) initiator, which has its peak action at $468 \mathrm{~nm}$ and is the most commonly used agent in resin-based materials. ${ }^{9}$ Multipeak LED units present violet light in addition to blue light with emission of wavelengths below $420 \mathrm{~nm}$, allowing the activation of different initiators. ${ }^{9}$

The light tips of the LCUs have different diameters, ${ }^{10}$ and their sizes often do not coincide with the mesiodistal dis- tances (MD-Ds) of the posterior teeth, which ranges from 6.74 to $7.16 \mathrm{~mm}$ in premolars and from 9.72 to $11.03 \mathrm{~mm}$ in molars. ${ }^{11}$ For the incremental technique, this factor may not be relevant given that each increment must be individually activated by light. However, for the use of bulk-fill resins, only one light-activation cycle is typically performed. Under these circumstances, the MD-D from the teeth and the diameter of the LED tip must be known to perform proper light curing to the whole restoration and consequently allow for sufficient polymerization. ${ }^{12}$ LCUs with small tip diameter used to activate large molar restorations may not completely cover the resin composite, potentially resulting in insufficient polymerization. ${ }^{7}$

Thus, the aim of this study was to evaluate the influence of different LED-based LCUs with different tip diameters and light spectra for activating bulk-fill RBCs. The null hypothesis generated was that LCUs with different tip sizes and light spectra would not influence the DC and Knoop hardness (KHN) of different bulk-fill RBCs.

\section{Materials and Methods}

\section{Irradiance Measurement}

The curing units, Valo (Ultradent, Salt Lake City, Utah, United States) and Radii Xpert (SDI, Bayswater, Australia) were fully charged as recommended by the manufacturer. The higher power $(\mathrm{mW})$ of the cordless LED units during the cycle was individually checked for five light cycles of 20 seconds using a power meter (Nova, Ophir Spiricon, Logan, Utah, United States), then the average of the five cycles was divided by the tip area $\left(\mathrm{cm}^{2}\right)$, calculated from the optical diameter, as measured with a digital caliper (CD6CS, Mitutoyo, Kanagawa, Japan), to obtain the irradiance $\left(\mathrm{mW} / \mathrm{cm}^{2}\right)(-$ Table $\mathbf{1}){ }^{13}$

\section{Specimen Preparation}

To simulate the diameter of average occlusal cavities in premolars and molars, 2-mm-thick resin cylinders with 7 and $10 \mathrm{~mm}$ diameter, respectively, were made from the conventional and bulk-fill composites as described in -Table 2. For this, circular aluminum matrixes were positioned over glass plates, and specimens were obtained by inserting the RBCs in a single increment. Then, a Mylar strip and a glass plate were placed over the resin and slightly compressed to regularize the top surface of the specimens.

For light curing the specimens, the tip of the LCU ( - Table 1 ) was positioned parallel and in close contact to the top glass plate, and light curing was performed for 20 seconds, as

Table 1 Specifications of the LCU tested

\begin{tabular}{|l|l|l|l|l|l|}
\hline LCU & Manufacturer & Irradiance & $\begin{array}{l}\text { Wavelength } \\
\text { emission }\end{array}$ & $\begin{array}{l}\text { Tip diameter } \\
\left(\mathrm{mm}^{18}\right.\end{array}$ & $\begin{array}{l}\text { Tip area } \\
\left(\mathrm{cm}^{2}\right)^{18}\end{array}$ \\
\hline Radii Xpert & $\begin{array}{l}\text { SDI, Bayswater, Victoria, } \\
\text { Australia }\end{array}$ & $1,575 \mathrm{~mW} / \mathrm{cm}^{2}$ (standard) & Monowave & 7.8 & 0.48 \\
\hline Valo & $\begin{array}{l}\text { Ultradent, Salt Lake City, } \\
\text { Utah, United States }\end{array}$ & $1103 \mathrm{~mW} / \mathrm{cm}^{2}$ (standard) & Multipeak & 9.5 & 0.7 \\
\hline
\end{tabular}

Abbreviation: LCU, light-curing unit. 
Table 2 Specifications of the tested RBCs

\begin{tabular}{|c|c|c|c|c|c|c|c|}
\hline $\begin{array}{l}\text { Resin } \\
\text { composite }\end{array}$ & Manufacturer & Color & Type & Organic matrix & Filler & $\begin{array}{l}\text { Amount } \\
\text { of load } \\
\text { (wt\%/vol\%) }\end{array}$ & $\begin{array}{l}\text { Batch } \\
\text { no. }\end{array}$ \\
\hline Amaris & $\begin{array}{l}\text { VOCO, Cuxhaven, } \\
\text { Germany }\end{array}$ & $\mathrm{TN}$ & $\begin{array}{l}\text { Conventional } \\
\text { Nanohybrid }\end{array}$ & $\begin{array}{l}\text { Bis-GMA, UDMA, } \\
\text { TEGDMA }\end{array}$ & $\begin{array}{l}\text { Inorganics fillers in a meth- } \\
\text { acrylate matrix }\end{array}$ & $80 /-$ & 1829623 \\
\hline Filtek One & $\begin{array}{l}\text { 3M ESPE, St. Paul, Min- } \\
\text { nesota, United States }\end{array}$ & $\mathrm{A} 2$ & Bulk fill & $\begin{array}{l}\text { AFM, AUDMA, UDMA, } \\
\text { and 1,2-dodecano-DMA } \\
\text { (DDMA) }\end{array}$ & $\begin{array}{l}\text { Ytterbium trifluoride, non- } \\
\text { aggregated silica, nonag- } \\
\text { gregated zirconia, } \\
\text { zirconia/silica clusters }\end{array}$ & $76.5 / 58$ & N974887 \\
\hline Aura Bulk Fill & $\begin{array}{l}\text { SDI, Bayswater, Victo- } \\
\text { ria, Australia }\end{array}$ & BKF & Bulk fill & $\begin{array}{l}\text { Bis-GMA, UDMA, Bis- } \\
\text { EMA, TEGDMA }\end{array}$ & $\begin{array}{l}\text { Silica, signaled barium and } \\
\text { glass particles }\end{array}$ & $74.2 / 65$ & 180143 \\
\hline Tetric Bulk Fill & $\begin{array}{l}\text { Ivoclar Vivadent, } \\
\text { Schaan, Liechtenstein }\end{array}$ & IVA & Bulk fill & $\begin{array}{l}\text { Bis-GMA, BisEMA and } \\
\text { UDMA }\end{array}$ & $\begin{array}{l}\text { Barium aluminum silicate } \\
\text { glass, an "Isofiller," ytterbi- } \\
\text { um fluoride and spherical } \\
\text { mixed oxide }\end{array}$ & $75-77 / 55$ & 94624 \\
\hline
\end{tabular}

Abbreviation: RBCs, resin-based composites.

recommended by each composite manufacturer, using a standardized position. The position of each specimen in relation to the LCU tip was noted in the top of the discs with permanent marker to allow the same position to be determined during the tests. After this, the specimens were stored under dry conditions in identified light-proof containers.

\section{Degree of Conversion}

Twenty-four hours after specimen preparation, the DC was evaluated at the center of the top surface of the specimens ( $n=10)$ using attenuated total reflectance Fourier-transform infrared (FTIR) spectroscopy unit (Tensor 27, Bruker, Ettlingen, Germany). To determine the number of carbon bonds remaining, a percentage was obtained between the aliphatic $\mathrm{C}=\mathrm{C}$ (vinyl) $\left(1,638 \mathrm{~cm}^{-1}\right)$ and aromatic $\mathrm{C}=\mathrm{C}$ absorption $\left(1,608 \mathrm{~cm}^{-1}\right)$ chains for both cured and uncured specimens. The spectra of cured and uncured specimens were obtained using 32 scans at $4 \mathrm{~cm}^{-1}$ resolution within 1,000 to $6,000 \mathrm{~cm}^{-1}$ range. The spectra were subtracted from the background spectra using the FTIR unit provided software (OMNIC 6.1, Nicolet 138 Instrument Corp, Madison, Wisconsin, United States). The DC was calculated using the following equation: DC $(\%)=(1-$ [cured aliphatic/aromatic ratio]/[uncured aliphatic/144 aromatic ratio] $) \times 100{ }^{6}$

\section{Knoop Hardness}

KHN specimens were included in polyester resin to allow for better handling during polishing and hardness tests. Then, the specimens were submitted to sequential wet polishing using sandpapers (\#100, 600, 1,200, 2,000, and 3,000 grit; $3 \mathrm{M}$, Sumaré, São Paulo, Brazil) in an automatized polisher for 1 minute in each polisher. Sequentially, the specimens received final polishing using felt discs associated with 1 and $0.25 \mu \mathrm{m}$ metallographic diamond pastes (Arotec, Cotia, São Paulo, Brazil) for 1 minute in each polisher. The specimens were then washed with deionized water.

After air-drying, the specimens were submitted to KHN tests (HMV-2; Shimadzu, Kyoto, Japan), which were performed on the top surface by applying a load of $100 \mathrm{~g}$ for 10 seconds. Fifteen indentations were performed in each specimen at five different areas with 3 indentations in the central area and 12 in the periphery with 3 in each extremity: superior, inferior, left, and right, $1 \mathrm{~mm}$ away from the margin of the disc. The KHN corresponding to each indentation was determined by measuring the dimensions of the indentation using the following formula: $\mathrm{KHN}=14.2$ ( $F=$ $d / d^{2}$ ), where $F$ is the test load in $\mathrm{kg}$, and $d$ is the longer diagonal length of an indentation in $\mathrm{mm}$. Then, the KHN value was determined by obtaining the arithmetic mean of indentations made in the center and peripheries. ${ }^{5}$

\section{Statistical Analysis}

The data collected for DC and KHN were assessed for homoscedasticity and submitted to three-way analysis of variance (ANOVA). Multiple comparisons were made using the Tukey's test within the experimental groups. One-way ANOVA followed by Dunnett's test was used for comparisons between control and experimental groups. All the tests were conducted at an $\alpha=0.05$ significance level. The analyses were performed using a statistical software (SigmaPlot 12.0, Systat Software, San Jose, California, United States).

\section{Results}

\section{Degree of Conversion}

The DC results are shown in - Tables 3 and 4. Tetric Bulk Fill exhibited increased DC compared with conventional resin composite for both diameters and LCUs evaluated. For Filtek One, significant differences from the control group were only observed for $10-\mathrm{mm}$ specimens light-cured with Radii Xpert, which presented increased DC. Aura Bulk Fill exhibited increased DC compared with the control group in almost all conditions. However, no significant differences were verified for $10-\mathrm{mm}$ specimens light-cured with Valo. None of the bulk-fill RBCs exhibited significantly reduced DC results compared with the control group. In most situations, bulk-fill RBCs exhibited superior or statistically similar DC results (-Table $\mathbf{3}$ ).

LCUs and specimen diameter significantly affected DC results compared with bulk-fill RBCs (- Table 4). The Tetric Bulk Fill showed increased DC results (54.8 and 53.5\% for 7 
Table 3 Mean DC\% values and standard deviation $( \pm)$ for control and experimental groups according to LCU and specimen diameter

\begin{tabular}{|c|c|c|c|c|c|c|c|}
\hline Group & Diameter & LCU & DC\% & $p$-Value & LCU & DC\% & $p$-Value \\
\hline \multirow[t]{2}{*}{ Amaris (CG) } & $7 \mathrm{~mm}$ & \multirow[t]{8}{*}{ Valo } & $47.2 \pm 3.6$ & - & Radii Xpert & $45.9 \pm 3.4$ & - \\
\hline & $10 \mathrm{~mm}$ & & $48.6 \pm 3.6$ & - & & $44.9 \pm 3.0$ & - \\
\hline \multirow[t]{2}{*}{ Aura Bulk Fill } & $7 \mathrm{~mm}$ & & $51.2 \pm 1.9^{\mathrm{a}}$ & 0.004 & & $51.7 \pm 3.0^{\mathrm{a}}$ & $<0.001$ \\
\hline & $10 \mathrm{~mm}$ & & $50.4 \pm 2.3$ & 0.344 & & $52.9 \pm 2.9^{a}$ & $<0.001$ \\
\hline \multirow[t]{2}{*}{ Filtek One } & $7 \mathrm{~mm}$ & & $49.7 \pm 2.7$ & 0.099 & & $47.0 \pm 2.0$ & 0.753 \\
\hline & $10 \mathrm{~mm}$ & & $49.6 \pm 2.8$ & 0.741 & & $52.4 \pm 2.2^{\mathrm{a}}$ & $<0.001$ \\
\hline \multirow[t]{2}{*}{ Tetric Bulk Fill } & $7 \mathrm{~mm}$ & & $54.8 \pm 1.7^{\mathrm{a}}$ & $<0.001$ & & $52.1 \pm 3.1^{\mathrm{a}}$ & $<0.001$ \\
\hline & $10 \mathrm{~mm}$ & & $53.5 \pm 1.5^{\mathrm{a}}$ & $<0.001$ & & $52.9 \pm 2.4^{\mathrm{a}}$ & $<0.001$ \\
\hline
\end{tabular}

Abbreviations: CG, control group; DC, degree of conversion; LCU, light-curing unit.

andicates significant difference from CG; one-way analysis of variance and Dunnett's test $(p>0.05)$.

Table 4 Mean DC\% and standard deviation $( \pm$ ) for bulk-fill RBCs according to LCU and specimen diameter

\begin{tabular}{|c|c|c|c|c|}
\hline \multirow[t]{2}{*}{ Group } & \multicolumn{2}{|l|}{ Valo } & \multicolumn{2}{|l|}{ Radii Xpert } \\
\hline & $7 \mathrm{~mm}$ & $10 \mathrm{~mm}$ & $7 \mathrm{~mm}$ & $10 \mathrm{~mm}$ \\
\hline Aura Bulk Fill & $\begin{array}{l}51.2 \pm 1.9 \\
\text { Ab€ }\end{array}$ & $\begin{array}{l}50.4 \pm 2.3 \\
\text { Ab€ }\end{array}$ & $\begin{array}{l}51.7 \pm 3.0 \\
\mathrm{Aa} €\end{array}$ & $\begin{array}{l}52.9 \pm 2.9 \\
\mathrm{Aa} €\end{array}$ \\
\hline Filtek One & $\begin{array}{l}49.7 \pm 2.7 \\
\mathrm{AbE}\end{array}$ & $\begin{array}{l}49.6 \pm 2.8 \\
\text { Ab€ }\end{array}$ & $\begin{array}{l}47.0 \pm 2.0 \\
\mathrm{AbE}\end{array}$ & $\begin{array}{l}52.4 \pm 2.2 \\
\mathrm{Ab} €\end{array}$ \\
\hline Tetric Bulk Fill & $\begin{array}{l}54.8 \pm 1.7 \\
\text { Aa€ }\end{array}$ & $\begin{array}{l}53.5 \pm 1.5 \\
\text { Aa€ }\end{array}$ & $\begin{array}{l}52.1 \pm 3.1 \\
\mathrm{Ba€}\end{array}$ & $\begin{array}{l}52.9 \pm 2.4 \\
\mathrm{Ba€}\end{array}$ \\
\hline
\end{tabular}

Abbreviations: DC, degree of conversion; LCU, light-curing unit; RBCs, resin-based composites.

Note: Capital letters indicate significant differences among LCUs (rows: vertical direction). Lowercase letters indicate significant differences among bulk-fill RBCs (columns: horizontal direction), and symbols indicate significant differences between diameters for the same LCU (rows: vertical direction). Tukey's test $(p<0.05)$.

and $10 \mathrm{~mm}$, respectively) when light-cured with Valo compared with Radii Xpert (52.1 and 52.9\%, respectively). When using Valo, Tetric Bulk Fill also presented superior DC results compared with the other bulk-fill RBCs evaluated. The Tetric Bulk Fill and Aura Bulk Fill presented superior DC results compared with Filtek One when light curing with Radii Xpert. Significant differences were observed for DC results for the different specimen diameters in the Filtek One group.

\section{Knoop Hardness}

The KHN results are described in - Tables 5 and $\mathbf{6}$. No significant differences were noted in KHN results for the conventional resin composite (Amaris) when comparing with LCUs $(p=0.213)$ or disc diameters $(p=0.587)$, but the center of the specimen exhibited superior KHN $(p \leq 0.001)$ compared with periphery. KHN results for Aura Bulk Fill were not influenced by LCUs $(p=0.049)$, specimen diameter $(p=0.468)$, or region of analysis $(p=0.083)$. For Filtek One, similar KHN results were verified for the different LCUs $(p=0.276)$, but 7-mm diameter specimens exhibited greater KHN than $10-\mathrm{mm}$ diameter specimens $(p=0.002)$, and the center region exhibited superior results compared with periphery ( $p=0.038$ ). For Tetric Bulk Fill, light curing with
Valo resulted in superior KHN compared with Radii Xpert ( $p \leq$ 0.001 ), and 7-mm specimens also presented increased KHN compared with $10-\mathrm{mm}$ diameter specimens ( $p=0.015$ ), but no significant differences were observed for the region of analysis.

None of the experimental groups showed significantly reduced KHN results compared with the control group (Amaris). The 7-mm Aura Bulk Fill specimens photoactivated with Valo were not statistically different compared with Amaris (control group). All other groups presented significantly superior KHN results compared with the control group (-Table 5).

\section{Discussion}

The LCUs tested in the present study present different tip diameters and light spectra and have influenced the DC and KHN of the bulk-fill RBCs tested. Thus, the null hypothesis tested was rejected.

The use of bulk-fill RBCs have increased substantially in recent years, and adequate light curing is essential to achieve the best mechanical properties with these materials. ${ }^{7}$ The polymerization process of light-cured composites is completely dependent on the technical characteristics of the LCU, such as irradiance, wavelength range, diameter of the tip, and others. ${ }^{14}$ Different LCUs can result in distinct physical properties for the same material given that the DC and hardness of RBCs may be affected as demonstrated by the results of this investigation and previous studies. ${ }^{15,16}$

Different mechanisms can be used to allow deeper polymerization and reduced stress for bulk-fill composites. Some manufacturers achieve deeper polymerization by using additional or different photoinitiators, such as diphenyl phosphine oxide (Lucerin-TPO) or bis-(4-methoxybenzoyl) diethyl-germane (Ivocerin). ${ }^{17}$ The properties of bulk-fill resins may also be improved when increased light transmission through the composite is possible, which its commonly achieved by changing the filler content. The presence of pigments and refractive index mismatch between the organic matrix and fillers are the main factors causing reduction in light transmission. ${ }^{18}$ 
Table 5 Mean KHN values and standard deviation $( \pm$ ) for control and experimental groups according to LCU, specimen diameter, and region of analysis

\begin{tabular}{|c|c|c|c|c|c|c|c|c|}
\hline Group & Diameter & Region & LCU & KHN & $p$-Value & LCU & KHN & $p$-Value \\
\hline \multirow[t]{4}{*}{ Amaris (CG) } & \multirow[t]{2}{*}{$7 \mathrm{~mm}$} & Center & Valo & $53.0 \pm 4.4$ & - & Radii Xpert & $51.3 \pm 1.0$ & - \\
\hline & & Periphery & & $51.8 \pm 3.7$ & - & & $48.8 \pm 0.8$ & - \\
\hline & \multirow[t]{2}{*}{$10 \mathrm{~mm}$} & Center & & $53.2 \pm 1.8$ & - & & $54.3 \pm 1.7$ & - \\
\hline & & Periphery & & $57.6 \pm 1.6$ & - & & $49.4 \pm 1.4$ & - \\
\hline \multirow[t]{4}{*}{ Aura Bulk Fill } & \multirow[t]{2}{*}{$7 \mathrm{~mm}$} & Center & & $57.6 \pm 2.5^{\mathrm{a}}$ & 0.032 & & $58.8 \pm 2.3^{\mathrm{a}}$ & $<0.001$ \\
\hline & & Periphery & & $55.3 \pm 2.2$ & 0.067 & & $57.0 \pm 1.9^{a}$ & $<0.001$ \\
\hline & \multirow[t]{2}{*}{$10 \mathrm{~mm}$} & Center & & $58.3 \pm 2.1^{\mathrm{a}}$ & $<0.001$ & & $57.5 \pm 1.7^{\mathrm{a}}$ & $<0.001$ \\
\hline & & Periphery & & $57.6 \pm 1.6^{a}$ & $<0.001$ & & $57.4 \pm 3.0^{a}$ & $<0.001$ \\
\hline \multirow[t]{4}{*}{ Filtek One } & \multirow[t]{2}{*}{$7 \mathrm{~mm}$} & Center & & $70.5 \pm 0.8^{\mathrm{a}}$ & $<0.001$ & & $69.9 \pm 1.7^{\mathrm{a}}$ & $<0.001$ \\
\hline & & Periphery & & $69.4 \pm 1.1^{\mathrm{a}}$ & $<0.001$ & & $69.7 \pm 0.8^{\mathrm{a}}$ & $<0.001$ \\
\hline & \multirow[t]{2}{*}{$10 \mathrm{~mm}$} & Center & & $68.9 \pm 2.1^{a}$ & $<0.001$ & & $69.0 \pm 1.1^{a}$ & $<0.001$ \\
\hline & & Periphery & & $68.5 \pm 2.0^{\mathrm{a}}$ & $<0.001$ & & $66.8 \pm 1.0^{\mathrm{a}}$ & $<0.001$ \\
\hline \multirow[t]{4}{*}{ Tetric Bulk Fill } & \multirow[t]{2}{*}{$7 \mathrm{~mm}$} & Center & & $62.1 \pm 0.9^{\mathrm{a}}$ & $<0.001$ & & $59.7 \pm 1.7^{\mathrm{a}}$ & $<0.001$ \\
\hline & & Periphery & & $61.7 \pm 0.7^{\mathrm{a}}$ & $<0.001$ & & $58.6 \pm 1.2^{\mathrm{a}}$ & $<0.001$ \\
\hline & \multirow[t]{2}{*}{$10 \mathrm{~mm}$} & Center & & $60.6 \pm 1.0^{\mathrm{a}}$ & $<0.001$ & & $58.1 \pm 2.6^{a}$ & $<0.001$ \\
\hline & & Periphery & & $60.0 \pm 0.8^{a}$ & $<0.001$ & & $57.4 \pm 1.9^{a}$ & $<0.001$ \\
\hline
\end{tabular}

Abbreviations: CG, control group; KHN, Knoop hardness; LCU, light-curing unit.

andicates significant difference from CG; one-way analysis of variance and Dunnett's test $(p>0.05)$.

Table 6 Mean Knoop hardness and standard deviation $( \pm$ ) for bulk-fill RBCs according to LCU, specimen diameter and region of analysis

\begin{tabular}{|c|c|c|c|c|c|}
\hline \multirow[t]{2}{*}{ Group } & \multirow[t]{2}{*}{ Diameter } & \multicolumn{2}{|l|}{ Valo } & \multicolumn{2}{|l|}{ Radii Xpert } \\
\hline & & Center & Periphery & Center & Periphery \\
\hline \multirow[t]{2}{*}{ Amaris } & $7 \mathrm{~mm}$ & $\begin{array}{l}53.0 \pm 4.4 \\
\text { AaE }\end{array}$ & $\begin{array}{l}51.8 \pm 3.7 \\
\operatorname{Baf}\end{array}$ & $\begin{array}{l}51.3 \pm 1.0 \\
\text { Aaf }\end{array}$ & $\begin{array}{l}48.8 \pm 0.8 \\
\mathrm{BaE}\end{array}$ \\
\hline & $10 \mathrm{~mm}$ & $\begin{array}{l}53.2 \pm 1.8 \\
\text { AaE }\end{array}$ & $\begin{array}{l}49.6 \pm 1.5 \\
\mathrm{BaE}\end{array}$ & $\begin{array}{l}54.3 \pm 1.7 \\
\text { Aa£ }\end{array}$ & $\begin{array}{l}49.4 \pm 1.4 \\
\mathrm{BaE}\end{array}$ \\
\hline \multirow[t]{2}{*}{ Aura Bulk } & $7 \mathrm{~mm}$ & $\begin{array}{l}57.6 \pm 2.5 \\
\text { AaE }\end{array}$ & $\begin{array}{l}55.3 \pm 2.2 \\
\mathrm{AaE}\end{array}$ & $\begin{array}{l}58.8 \pm 2.3 \\
\text { Aaf }\end{array}$ & $\begin{array}{l}57.0 \pm 1.9 \\
\mathrm{AaE}\end{array}$ \\
\hline & $10 \mathrm{~mm}$ & $\begin{array}{l}58.3 \pm 2.1 \\
\text { AaE }\end{array}$ & $\begin{array}{l}57.6 \pm 1.6 \\
\text { AaE }\end{array}$ & $\begin{array}{l}57.5 \pm 1.7 \\
\text { Aaf }\end{array}$ & $\begin{array}{l}57.4 \pm 3.0 \\
\mathrm{AaE}\end{array}$ \\
\hline \multirow[t]{2}{*}{ Filtek One } & $7 \mathrm{~mm}$ & $\begin{array}{l}70.5 \pm 0.8 \\
\text { AaE }\end{array}$ & $\begin{array}{l}69.4 \pm 1.1 \\
\mathrm{BaE}\end{array}$ & $\begin{array}{l}69.9 \pm 1.7 \\
\text { Aaf }\end{array}$ & $\begin{array}{l}69.7 \pm 0.8 \\
\text { AaE }\end{array}$ \\
\hline & $10 \mathrm{~mm}$ & $\begin{array}{l}68.9 \pm 2.1 \\
\mathrm{AbE}\end{array}$ & $\begin{array}{l}68.5 \pm 2.0 \\
\mathrm{Bb} £\end{array}$ & $\begin{array}{l}69.0 \pm 1.1 \\
\mathrm{Abf}\end{array}$ & $\begin{array}{l}66.8 \pm 1.0 \\
\mathrm{AbE}\end{array}$ \\
\hline \multirow[t]{2}{*}{ Tetric Bulk } & $7 \mathrm{~mm}$ & $\begin{array}{l}62.1 \pm 0.9 \\
\text { Aaf }\end{array}$ & $\begin{array}{l}61.7 \pm 0.7 \\
\text { AaE }\end{array}$ & $\begin{array}{l}59.7 \pm 1.7 \\
\mathrm{Aa} €\end{array}$ & $\begin{array}{l}58.6 \pm 1.2 \\
\mathrm{Aa} €\end{array}$ \\
\hline & $10 \mathrm{~mm}$ & $\begin{array}{l}60.6 \pm 1.0 \\
A b £\end{array}$ & $\begin{array}{l}60.0 \pm 0.8 \\
A b £\end{array}$ & $\begin{array}{l}58.1 \pm 2.6 \\
A b €\end{array}$ & $\begin{array}{l}57.4 \pm 1.9 \\
\text { Ab€ }\end{array}$ \\
\hline
\end{tabular}

Abbreviations: DC, degree of conversion; LCU, light-curing unit; RBCs, resin-based composites.

Note: Capital letters indicate significant differences between center and periphery regions (rows: vertical direction). Lowercase letters indicate significant differences between disc diameters (columns: horizontal direction), and symbols indicate significant differences between LCUs for the same region (rows: vertical direction). Tukey's test $(p<0.05)$.

In the present study, no bulk-fill RBCs presented lower DC values than the conventional composite (control group). The LCU factor was only relevant for Tetric N-Ceram Bulk Fill, and this may be explained by the fact that this material has an additional initiator to $\mathrm{CQ}$, Ivocerin, which is most reactive at
$408 \mathrm{~nm}$ but remains sensitive to wavelengths between 400 and $430 \mathrm{~nm} .{ }^{19}$ This spectrum of light is present in Multipeak LCUs with wavelength peaks at 405,440 , and $460 \mathrm{~nm}$ but not in the Monowave LCUs, which commonly present a wavelength peak $\sim 460 \mathrm{~nm} .{ }^{20}$ For the other bulk-fill RBCs in which 
the manufacturer does not mention the initiator used or only $\mathrm{CQ}$ is present, the light spectrum emitted from the Monowave LCU was sufficient to achieve similar DC to that obtained with the Multipeak LCU. The manufacturers of the bulk-fill RBCs used in this study do not completely indicate the specific initiators and the number of initiators used in these materials. The limitation of this test was that the size of the FTIR reading platform only allowed readings to be performed in the center of the specimens, and it was not possible to analyze the DC in peripheral areas.

The hardness of dental materials is an important aspect for the selection of different restorative approaches on posterior teeth. ${ }^{5}$ In the present study, no bulk-fill RBCs presented lower KHN values than the convectional composite tested. Only Aura Bulk Fill 7-mm specimens light-cured by Valo exhibited similar KHN results to the control group, and the other experimental groups exhibited superior KHN in all conditions evaluated. Filtek One exhibited higher KHN results compared with the other RBCs, and a possible explanation may be the different monomers and filler composition present in this material (-Table 1). Regarding the DC, LCU was the only relevant factor for the Tetric N-Ceram Bulk Fill groups.

There is a high demand for Class II restorations, which have an annual failure rate of $1.68 \%$ over 12 years. ${ }^{21}$ Conventional and bulk-fill RBCs are suitable materials for these restorations. ${ }^{14,15,22}$ Clinically, several LCUs present smaller tips compared with the restorative area that needs to be reached by light (10). Mesioocclusodistal (MOD) cavities, such as those noted in first maxillary molars with a $10.31-\mathrm{mm}$ mean MD$\mathrm{D}$, second maxillary molars $(9.79 \mathrm{~mm} \mathrm{MD}-\mathrm{D})$, and first (6.98 $\mathrm{mm}$ MD-D) or second maxillary premolars $(6.74 \mathrm{~mm}$ MD-D) may present superior dimensions compared with the LCU tip. ${ }^{11}$ Thus, the specimens in this study exhibited two different diameters: $7 \mathrm{~mm}$ (equivalent to maxillary premolars MD-D) and $10 \mathrm{~mm}$ (equivalent to maxillary molars MD-D).

The conventional composite Amaris and the Filtek One bulk-fill exhibited variations in KHN, which were verified at the central and peripheric regions of the specimens. KHN measurements were performed at the top of the specimens given that the main objective was to verify the influence of the LCU tip diameter and not the polymerization depth. The central region of the Amaris and Filtek One specimens exhibited increased KHN values compared with the periphery. These results are consistent with previous studies that reported similar findings. ${ }^{7,23}$ The Tetric $\mathrm{N}$-Ceram and Aura bulk-fill RBCs presented similar hardness values at the center and periphery. This fact can be justified by the composition of the organic matrix in these composites that allows greater dispersion of light or the presence of additional initiators that may consequently lead to favorable physical properties in the periphery. ${ }^{24,25}$

The Valo LCU has four LEDs positioned in the different quarters of the tip diameter, which results in a nonuniform wavelength light beam emission because three LEDs emit blue light (two with peak emission at $460 \mathrm{~nm}$ and one with at $440 \mathrm{~nm}$ ) and one LED emits violet light (peak emission at $405 \mathrm{~nm}){ }^{20}$ Despite this fact, no differences in KHN were assessed in the center or periphery of the specimens for the bulk-fill resin composite with the additional initiator (Ivocerin). This finding indicates that the rotation angle of the light tip from multipeak LCUs may not affect the properties of RBCs with different photoinitiators from $C Q$. The KHN test was performed at the top of the specimens to analyze the possibilities of using bulk-fill composited in wide cavities, allowing a single increment to be used in such situations. This is important, since in the incremental technique, it should be avoided joining antagonistic walls in one increment, such as buccal with lingual and mesial with distal walls. ${ }^{26}$

LCUs with small-diameter tips should not be an issue if an incremental filling technique is used. ${ }^{7}$ However, reduced light tips may become a problem when a bulk technique is used for extensive MOD restorations. Additional light exposure in the peripheric regions of MOD and larger cavities in posterior teeth is subsequently recommended. ${ }^{23}$ Thus, clinicians can assure that all bulk-fill resins receive proper light irradiance, even when using LCUs with small tips. To minimize this problem, additional light exposure in the mesial and distal regions is suggested. LCUs with wide tips and longer exposure times are preferred when light-curing MOD or other large restorations. ${ }^{23}$

Despite the limitations of mechanical laboratory tests, they can provide better understanding of fragile materials that are more likely to fail early as RBCs. ${ }^{27,28}$ The light beam profile provides information on the irradiance distribution from LCUs, ${ }^{8}$ and the light emitted from LCUs influences the polymerization of light-cured RBCs and consequently its properties. ${ }^{6}$ Several LCUs present very irregular beam profiles with very high irradiance values at the center of the tip and low values or even no irradiance at the periphery. Thus, the effective light-curing area can be even smaller than the tip of the device. ${ }^{8,23}$ Despite this, the mold and the diameter used for preparing the specimens can influence the DC of the composites. As one of the factors analyzed in this study was the restoration dimension (specimen diameter), it was not possible to standardize the diameter between specimens. ${ }^{29}$

The distance from the tip of the LCU to the restoration can also influence the irradiance reaching the material and consequently its physical properties. ${ }^{30}$ In this study, tests were performed with the LCU in close contact to the RBCs. This condition represent the ideal condition, but there are clinical situations in which it is not possible to place the LCU tip in close contact to the restoration, such as in deep cavities larger than $5 \mathrm{~mm}$ and proximal regions with adjacent teeth. ${ }^{31}$ In addition, LCUs are generally poorly maintained in dental offices and can deliver inadequate light output. ${ }^{6}$ This is a limitation of the present study, as light was always delivered from a favorable position and the LCUs were maintained in ideal conditions.

Therefore, clinicians should be aware that the properties of the restoration are material dependent, and bulk-fill RBCs available on the market may present very distinct physical properties. In addition, it is also important to distinguish the initiators present in the resin composites that are used in routine practice and the emission spectrum of the LCU given that these aspects are important to achieve adequate mechanical properties for RBCs. Unfortunately, some manufacturers 
do not provide this information. Studies are necessary to further investigate the relationship between the tip diameter of LCUs and the properties of RBCs.

\section{Conclusion}

Within the limitations of the present study, it was possible to observe that the light spectrum of the multipeak LCU significantly increased the DC and KHN of a bulk-fill resin composite with additional initiator to $\mathrm{CQ}$, compared with the monowave LCU. LCU tip size influenced the performance of some RBCs tested. The influence of LCU on the properties of RBCs is material dependent.

\section{Funding}

This study was partially supported by the Minas Gerais State Agency for Research and Development (FAPEMIG: grant CDS APQ 03963/16).

\section{Conflict of Interest}

None declared.

\section{References}

1 Opdam NJ, van de Sande FH, Bronkhorst E, et al. Longevity of posterior composite restorations: a systematic review and metaanalysis. J Dent Res 2014;93(10):943-949

2 Mantri SP, Mantri SS. Management of shrinkage stresses in direct restorative light-cured composites: a review. J Esthet Restor Dent 2013;25(05):305-313

3 Hickel R, Roulet JF, Bayne S, et al. Recommendations for conducting controlled clinical studies of dental restorative materials. Clin Oral Investig 2007;11(01):5-33

4 Veloso SRM, Lemos CAA, de Moraes SLD, do Egito Vasconcelos BC, Pellizzer EP, de Melo Monteiro GQ. Clinical performance of bulkfill and conventional resin composite restorations in posterior teeth: a systematic review and meta-analysis. Clin Oral Investig 2019;23(01):221-233

5 Cerda-Rizo ER, de Paula Rodrigues M, Vilela A, et al. Bonding interaction and shrinkage stress of low-viscosity bulk fill resin composites with high-viscosity bulk fill or conventional resin composites. Oper Dent 2019;44(06):625-636

6 Pereira AG, Raposo L, Teixeira D, et al. Influence of battery level of a cordless LED unit on the properties of a nanofilled composite resin. Oper Dent 2016;41(04):409-416

7 Shimokawa CAK, Turbino ML, Giannini M, Braga RR, Price RB. Effect of light curing units on the polymerization of bulk fill resinbased composites. Dent Mater 2018;34(08):1211-1221

8 Price RB, Labrie D, Rueggeberg FA, Sullivan B, Kostylev I, Fahey J. Correlation between the beam profile from a curing light and the microhardness of four resins. Dent Mater 2014;30(12):1345-1357

9 Sahadi BO, Price RB, André CB, et al. Multiple-peak and singlepeak dental curing lights comparison on the wear resistance of bulk-fill composites. Braz Oral Res 2018;32:e122

10 Soares CJ, Rodrigues MP, Oliveira LRS, et al. An Evaluation of the Light Output from 22 Contemporary Light Curing Units. Braz Dent J 2017;28(03):362-371

11 Lombardo L, Marcon M, Arveda N, La Falce G, Tonello E, Siciliani G. Preliminary biometric analysis of mesiodistal tooth dimensions in subjects with normal occlusion. Am J Orthod Dentofacial Orthop 2016;150(01):105-115

12 Merz ML, Isaacson RJ, Germane N, Rubenstein LK. Tooth diameters and arch perimeters in a black and a white population. Am J Orthod Dentofacial Orthop 1991;100(01):53-58
13 Shimokawa CA, Turbino ML, Harlow JE, Price HL, Price RB. Light output from six battery operated dental curing lights. Mater Sci Eng C 2016;69:1036-1042

14 Cardoso IO, Machado AC, Teixeira D, Basílio FC, Marletta A, Soares $\mathrm{PV}$. Influence of different cordless light-emitting-diode units and battery levels on chemical, mechanical, and physical properties of composite resin. Oper Dent 2020;45(04):377-386

15 Pirmoradian M, Hooshmand T, Jafari-Semnani S, Fadavi F. Degree of conversion and microhardness of bulk-fill dental composites polymerized by LED and QTH light curing units. J Oral Biosci 2020; 62(01):107-113

16 Al-Zain AO, Eckert GJ, Platt JA. The influence of distance on radiant exposure and degree of conversion using different light-emittingdiode curing units. Oper Dent 2019;44(03):E133-E144

17 Menees TS, Lin CP, Kojic DD, Burgess JO, Lawson NC. Depth of cure of bulk fill composites with monowave and polywave curing lights. Am J Dent 2015;28(06):357-361

18 Shortall AC, Palin WM, Burtscher P. Refractive index mismatch and monomer reactivity influence composite curing depth.J Dent Res 2008;87(01):84-88

19 Sampaio CS, Pizarro PG, Atria PJ, Hirata R, Giannini M, Mahn E. Effect of shortened light-curing modes on bulk-fill resin composites. Oper Dent 2020;45(05):496-505

20 de Oliveira D, Rocha MG, Correr AB, Ferracane JL, Sinhoreti M. Effect of beam profiles from different light emission tip types of multiwave light-emitting diodes on the curing profile of resinbased composites. Oper Dent 2019;44(04):365-378

21 Opdam NJ, Bronkhorst EM, Loomans BA, Huysmans MC. 12-year survival of composite vs. amalgam restorations. J Dent Res 2010; 89(10):1063-1067

22 Durão MA, Andrade AKM, Santos MDCMDS, Montes MAJR, Monteiro GQM. Clinical performance of bulk-fill resin composite restorations using the United States Public Health Service and Federation Dentaire Internationale Criteria: a 12-month randomized clinical trial. Eur J Dent 2021;15(02): 179-192

23 Shimokawa C, Turbino ML, Giannini M, Braga RR, Price RB. Effect of curing light and exposure time on the polymerization of bulkfill resin-based composites in molar teeth. Oper Dent 2020;45 (03):E141-E155

24 Amirouche-Korichi A, Mouzali M, Watts DC. Effects of monomer ratios and highly radiopaque fillers on degree of conversion and shrinkage-strain of dental resin composites. Dent Mater 2009;25 (11):1411-1418

25 Bin Nooh AN, Nahedh HA, AlRefeai M, Alkhudhairy F. The effect of irradiance on the degree of conversion and volumetric polymerization shrinkage of different bulk-fill resin-based composites: an in vitro study. Eur J Dent 2021;15(02):312-319

26 Bicalho AA, Pereira RD, Zanatta RF, et al. Incremental filling technique and composite material-part I: cuspal deformation, bond strength, and physical properties. Oper Dent 2014;39(02): E71-E82

27 Ilie N, Hilton TJ, Heintze SD, et al. Academy of Dental Materials guidance-resin composites: part I-mechanical properties. Dent Mater 2017;33(08):880-894

28 Magalhães Filho TR, Weig KM, Costa MF, Werneck MM, Barthem $\mathrm{RB}$, Costa Neto CA. Effect of LED-LCU light irradiance distribution on mechanical properties of resin based materials. Mater Sci Eng C 2016;63:301-307

29 Price RB, Rueggeberg FA, Harlow J, Sullivan B. Effect of mold type, diameter, and uncured composite removal method on depth of cure. Clin Oral Investig 2016;20(07):1699-1707

30 Corciolani G, Vichi A, Davidson CL, Ferrari M. The influence of tip geometry and distance on light-curing efficacy. Oper Dent 2008; 33(03):325-331

31 Lima RBW, Troconis CCM, Moreno MBP, Murillo-Gómez F, De Goes MF. Depth of cure of bulk fill resin composites: a systematic review. J Esthet Restor Dent 2018;30(06):492-501 